\title{
Wpływ dodatku tytanu w spoiwach cynkowych na zwilżalność powierzchni i właściwości mechaniczne aluminiowych połączeń lutowanych
}

\author{
Effect of titanium addition in zinc filler metal \\ on wettability and mechanical properties \\ of aluminum soldered joints
}

\section{Streszczenie}

Lutowaniu aluminium towarzyszy wiele problemów wynikających z właściwości fizykochemicznych metalu - w szczególności niskiej temperatury topnienia aluminium i trudności $z$ doborem lutu dobrze zwilżającego powierzchnię metalu oraz niepowodującego erozji materiału podstawowego. Wykonano badania przydatności do lutowania aluminium stopów Zn-Al, czystego cynku oraz cynku z dodatkiem tytanu jako spoiwa. Przedstawiono wyniki badań mechanicznych i metalograficznych wykonanych połączeń lutowanych.

\section{Wstęp}

Podstawowymi zjawiskami zachodzącymi podczas procesu lutowania jest zwilżalność i ściśle z nią powiązana rozpływność lutu na materiale podstawowym.

Od rozpływności określanej jako zdolność pokrywania powierzchni lutowanych części cienką, równomierną i nieprzerwaną powłoką ciekłego lutu zależy stopień wypełnienia szczeliny lutowniczej i ostatecznie jakość połączenia lutowanego. W pewnym uproszczeniu można stwierdzić, że im większa jest zdolność lutu do rozpływania się po powierzchni elementu lutowanego, tym większa jest jego przydatność do lutowania.

Dr inż. Maciej Różański - Instytut Spawalnictwa w Gliwicach.
Zwilżanie powierzchni metalu lub stopu lutem prowadzi przeważnie do tworzenia roztworów stałych lub faz międzymetalicznych i na odwrót - jeżeli metale stanowiące składniki lutu i materiału lutowanego nie rozpuszczają się wzajemnie oraz nie tworzą faz międzymetalicznych, zwykle nie dochodzi do zwilżenia lutem materiału łączonego. Przykładem jest aluminium, które doskonale rozpuszcza się w ciekłym cynku. Zgodnie z układem równowagi fazowej Zn-Al w temperaturze $382^{\circ} \mathrm{C}$ oba metale tworzą roztwór stały aż do granicznej zawartości 83,1\% wag. Al. Tak znaczna rozpuszczalność składników materiału podstawowego w lucie determinuje dobrą zwilżalność powierzchni aluminium ciekłym cynkiem.

Aluminium powszechnie uznawane jest za materiał trudnolutowalny. Decydują o tym takie właściwości, jak:

- stosunkowo niska temperatura topnienia aluminium $\left(658^{\circ} \mathrm{C}\right)$, utrudniająca dobór spoiwa;

- duże powinowactwo chemiczne do tlenu przy zetknięciu z powietrzem i pokrywanie trudno topliwą 
$\left(2050^{\circ} \mathrm{C}\right)$, trwałą chemicznie $(1116,3 \mathrm{~kJ} / \mathrm{mol} \mathrm{O})$ i szczelną powłoką trudno zwilżalnego przez luty tlenku $\mathrm{Al}_{2} \mathrm{O}_{3}$;

- ograniczone właściwości wytrzymałościowe, zwłaszcza w temperaturze powyżej $500^{\circ} \mathrm{C}$;

- wysoka przewodność $237 \mathrm{~W} /(\mathrm{m} \cdot \mathrm{K})$ i rozszerzalność cieplna $(0,00261 / \mathrm{K})$ oraz znaczny skurcz objętościowy (7\%) - sprzyjające występowaniu naprężeń i odkształceń cieplnych;

- potencjał elektrochemiczny (-1,66 V) odbiegający znacznie od potencjałów metali stanowiących podstawowe składniki lutów, co jest często przyczyną niskiej odporności na korozję połączeń lutowanych. Podstawowym lutem do lutowania twardego aluminium jest stop eutektyczny Al-Si o zawartości $12 \%$ krzemu i temperaturze topnienia $577^{\circ} \mathrm{C}$. Tak wysoka temperatura topnienia lutu wraz $z$ silną tendencją aluminium do erozji podczas kontaktu z ciekłym stopem eutektycznym Al-Si powoduje duże trudności podczas lutowania, polegające na rozpuszczaniu elementu lutowanego. Ten stop eutektyczny stanowi jednak dobrą podstawę do modyfikacji składu chemicznego celem obniżenia temperatury topnienia lutu i ograniczenia zjawiska erozji elementów lutowanych. Dodatek miedzi do stopu AISi12 w ilości $20 \%$ wag. powoduje obniżenie temperatury topnienia do $522 \div 535^{\circ} \mathrm{C}$. Dodatek $20 \%$ cynku natomiast umożliwia dalsze obniżenie temperatury do $500^{\circ} \mathrm{C}$. Duża zawartość miedzi w stopach Al-Si powoduje jednak podczas lutowania wydzielanie się eutektyki $\alpha$-CuAl2 powodującej dużą kruchość połączeń lutowanych [1]. Alternatywę do stosowania spoiw siluminowych do lutowania aluminium stanowi stosowanie spoiw cynkowych. Niska temperatura topnienia cynku $\left(420^{\circ} \mathrm{C}\right)$ i jeszcze niższa stopów z układu równowagi $\mathrm{Zn}-\mathrm{Al}$ (temperatura topnienia stopu eutektycznego Zn96Al4 - 384 $\mathrm{C}$ ) zmniejszają niebezpieczeństwo zniszczenia lutowanych elementów aluminiowych przez ich erozję czy rozpuszczenie w ciekłym lucie.

Do najczęściej stosowanych spoiw cynkowych zaliczane są stopy: ZnAl2, ZnAl4, ZnAl5, ZnAl15 oraz ZnAl22. Czysty cynk zwykle nie jest stosowany ze względu na niskie właściwości mechaniczne uzyskiwanych połączeń [2, 3]. Zwiększanie zawartości aluminium w stopach Zn-Al powoduje zwiększanie zwilżalności i rozpływności stopu na powierzchni metalu oraz zwiększenie wytrzymałości uzyskiwanych połączeń. Na przykład w pracy [4] podano, że rozpływność stopów ZnAl5, ZnAl15 i ZnAl22 na powierzchni aluminium EN AW - 3003 wynosi odpowiednio 245, 340 i $360 \mathrm{~mm}^{2}$. Zwiększenie udziału aluminium w stopie Zn-Al do zawartości $12 \%$ wag. powoduje zwiększanie wytrzymałości uzyskiwanych połączeń. Przekroczenie tej zawartości aluminium w spoiwie cynkowym powoduje ponowne zmniejszenie wytrzymałości mechanicznej połączeń lutowanych [4]. Przedstawiony wpływ zwiększenia zawartości aluminium w stopach Zn-Al na zwilżalność i właściwości wytrzymałościowe uzyskanych połączeń lutowanych należy uwzględnić przy doborze spoiwa, tak aby uzyskać możliwie dużą zwilżalność przy zachowaniu odpowiednio dużych właściwości wytrzymałościowych połączeń. Dlatego też przyjmuje się, że stosowanie stopu ZnAl22 o stosunkowo dużej zawartości Al uzasadnione jest jedynie w przypadku wymaganej wysokiej odporności korozyjnej połączeń. Właściwości mechaniczne uzyskanych przy jego użyciu połączeń są niższe niż właściwości połączeń wykonanych przy użyciu spoiw z mniejszą zawartością Al [6].

Prawdopodobnym rozwiązaniem problemu poprawy właściwości lutowniczych i wytrzymałościowych spoiw cynkowych może być stosowanie stopów cynku z domieszką tytanu. W pracy [5] wykazano, że niewielki dodatek tytanu (do ok. 0,1\%) do stopu ZnAl20 powoduje znaczne rozdrobnienie ziarna stopu oraz zwiększenie jego wytrzymałości o ok. $10 \%$ w stosunku do wytrzymałości tego samego stopu niemodyfikowanego tytanem. Ponadto uznano, że tytan jako pierwiastek aktywny, tworzący liczne fazy międzymetaliczne z większością metali, w tym również $z$ aluminium, powinien znacząco zwiększać zdolność zwilżania powierzchni aluminium spoiwami cynkowymi.

W niniejszym artykule porównano właściwości lutownicze wybranych stopów Zn-Al oraz zbadano możliwość zastosowania cynku z dodatkiem tytanu jako spoiwa do lutowania aluminium.

\section{Badania własne}

\section{Materiały do badań}

Jako materiału podstawowego do badań użyto aluminium EN AW - 1050 wg PN-EN 573-3 o składzie chemicznym podanym w tablicy I. Do badań rozpływności oraz wykonania próbnych połączeń zakładkowych do badań metalograficznych zastosowano próbki z blachy o wymiarach 40x40x3 mm. Do badań wytrzymałości na ścinanie wykorzystano pręt wyciskany cięty na próbki walcowe o wymiarach ø 20x15 mm.

Jako lutu użyto czystego cynku, cynku z dodatkiem tytanu oraz stopu Zn-Al. Skład chemiczny oraz temperaturę topnienia i postać zastosowanych lutów przedstawiono w tablicy II. Do prób rozpływności użyto topników niekorozyjnych: Aluflux NC Powder, Aluflux Cs Powder firmy Firinit oraz NOCOLOK® firmy Solvay. Zakres temperatury aktywności ww. topników wynosi odpowiednio: $570 \div 610^{\circ} \mathrm{C}, 420 \div 450^{\circ} \mathrm{C}$ oraz $564 \div 700^{\circ} \mathrm{C}$. Wszystkie topniki występują w postaci proszku. Zawiesinę proszku ułatwiającą nanoszenie topnika na powierzchnię aluminium uzyskiwano przez rozpuszczanie topnika w alkoholu etylowym w przypadku topników Aluflux NC Powder i Aluflux Cs Powder oraz w alkoholu izopropylowym w przypadku topnika NOCOLOK®. 
Tablica I. Skład chemiczny aluminium EN AW-1050

Table I. Chemical composition of EN AW-1050 aluminium

\begin{tabular}{|c|c|c|c|c|c|}
\hline \multicolumn{5}{|c|}{ Skład chemiczny, \% wag. } \\
\hline Al min & Si & Fe & Cu & Zn \\
\hline 99,5 & 0,25 & 0,40 & 0,05 & 0,05 \\
\hline Uwaga: W tablicy, z wyjątkiem zawartości aluminium, podano maksymalne zawartości pierwiastków. \\
\hline
\end{tabular}

Tablica II. Skład chemiczny, temperatura topnienia oraz postać stosowanych lutów cynkowych

Table II. Chemical composition, melting point and the shape of zinc solder

\begin{tabular}{|c|c|c|c|c|c|}
\hline \multirow{2}{*}{$\begin{array}{c}\text { Oznaczenie } \\
\text { lutu }\end{array}$} & \multicolumn{3}{|c|}{ Skład chemiczny, \% wag. } & \multirow{2}{*}{$\begin{array}{l}\text { Zakres temp. } \\
\text { topnienia, }{ }^{\circ} \mathrm{C}\end{array}$} & \multirow{2}{*}{ Postać } \\
\hline & $\mathrm{Zn}$ & $\mathrm{Al}$ & $\mathrm{Ti}$ & & \\
\hline $\mathrm{Zn}$ & 99,99 & - & - & 420 & pręt ø 2 \\
\hline ZnAl4 & 96 & 4 & - & $382-418$ & drut $\varnothing 1,6$ \\
\hline ZnAl15 & 85 & 15 & - & $382-450$ & drut $\varnothing 1,0$ \\
\hline $\mathrm{Zn}+\mathrm{Ti}$ & 99,93 & - & 0,07 & 419 & taśma $0,5 \mathrm{~mm}$ \\
\hline
\end{tabular}

\section{Próba rozpływności}

Badanie właściwości lutowniczych materiałów dodatkowych przeprowadzono, stosując klasyczną próbę rozpływności na próbkach aluminiowych (EN AW 1050) o wymiarach 40x40x3 mm. Bezpośrednio przed badaniem próbki odtłuszczono acetonem, a następnie kładziono na ich powierzchni lut o masie ok $0,5 \mathrm{~g}$ oraz zawiesinę topnikową o masie ok $0,2 \mathrm{~g}$. Próbki z naniesionym lutem oraz topnikiem umieszczano $\mathrm{w}$ specjalnym uchwycie i ogrzewano od dołu płomieniem tlenowo-acetylenowym aż do momentu rozpłynięcia się lutu. Podczas badania rozpływności oprócz powierzchni rozpłynięcia się lutu oceniano wizualnie przebieg topienia lutu, a także, po zakończeniu procesu, jakość i ilość pozostałego na powierzchni próbki żużla potopnikowego. W celu obliczania pól powierzchni rozpłynięcia się lutu na powierzchni aluminium wstawiono zdjęcia próbek jako obraz rastrowy do programu AutoCAD, obrysowano powierzchnię pokrytą lutem i odczytano powierzchnię zaznaczonego obszaru. Wyniki pomiaru rozpływności przedstawiono w tablicy III i na rysunku 1.

Tablica III. Wyniki prób rozpływności wybranych lutów cynkowych na powierzchni aluminium EN AW - 1050 przy użyciu różnych topników Table III. Results of the wetting tests of selected zinc solders on the EN AW-1050 aluminum surface, with the use of various fluxes

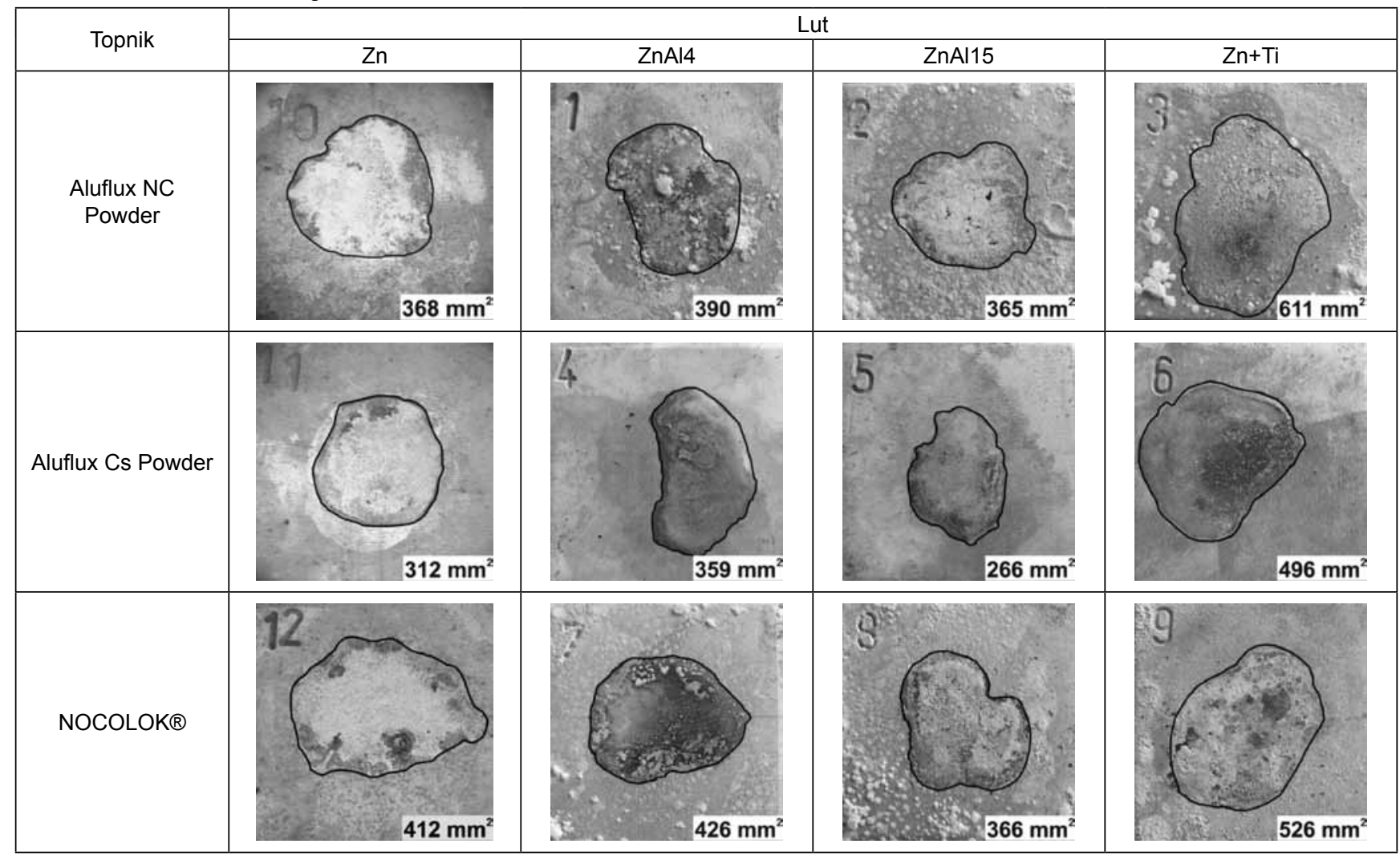




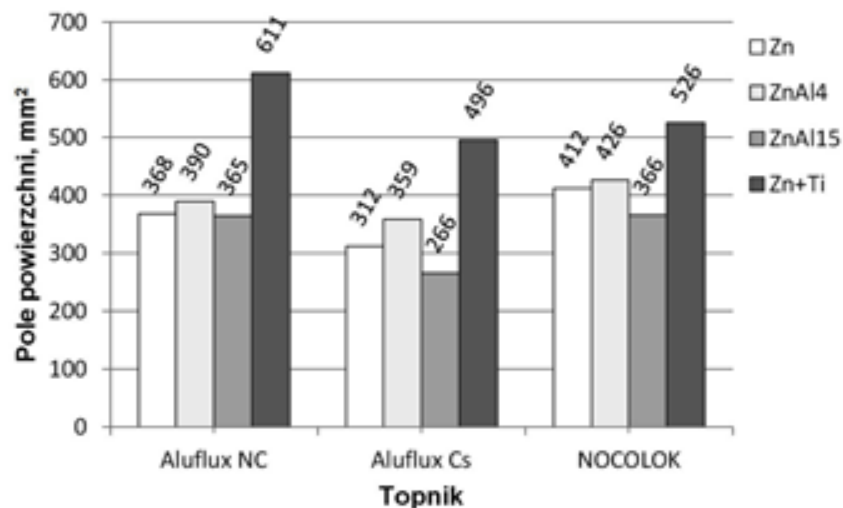

Rys. 1. Wyniki próby rozpływności lutów cynkowych na powierzchni aluminium

Fig. 1. Results of wetting tests for selected zinc solder on the aluminum surface

W przypadku każdego ze stosowanych topników najwyższą rozpływność spośród użytych lutów wykazywał lut cynkowy $z$ dodatkiem tytanu, oznaczony jako $\mathrm{Zn}+\mathrm{Ti}$, przy czym dla topnika Aluflux NC Powder pole powierzchni rozpłynięcia lutu wynosiło $611 \mathrm{~mm}^{2}$, dla topnika Aluflux Cs Powder $-496 \mathrm{~mm}^{2}$, a dla topnika NOCOLOK® $-526 \mathrm{~mm}^{2}$. Wyniki badań nie potwierdziły informacji literaturowych dotyczących zwiększenia zwilżalności stopami Zn-Al powierzchni aluminium wraz ze wzrostem w nich zawartości aluminium.

Ze względu na wysoką temperaturę aktywności topników Aluflux NC Powder oraz NOCOLOK@ powierzchnie próbek po próbie rozpływności pokryte były nieprzereagowanymi, bardzo trudno usuwalnymi pozostałościami potopnikowymi. Należy zauważyć, że pomimo najmniejszej rozpływności lutów cynkowych z użyciem topnika Aluflux Cs Powder, topnik ten całkowicie przereagowuje $w$ stosunkowo niskiej temperaturze lutowania i dlatego użyto go do wykonania połączeń próbnych do badań wytrzymałości na ścinanie.

\section{Wytrzymałość na ścinanie połączeń lutowanych}

Próby wytrzymałościowe $z$ użyciem polutowanych próbek w postaci walcowej wykonano przez ich ścinanie

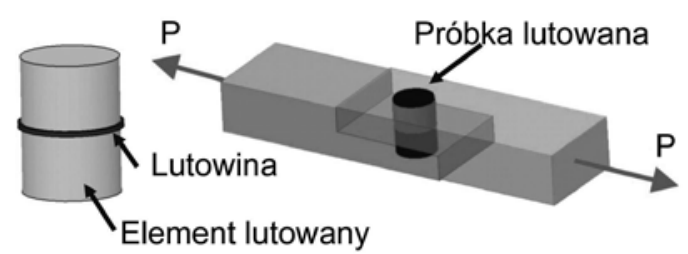

Rys. 2. Próbka lutowana i oprzyrządowanie pomocnicze do statycznej próby ścinania

Fig. 2. Soldered specimen and the equpment for static shearing test

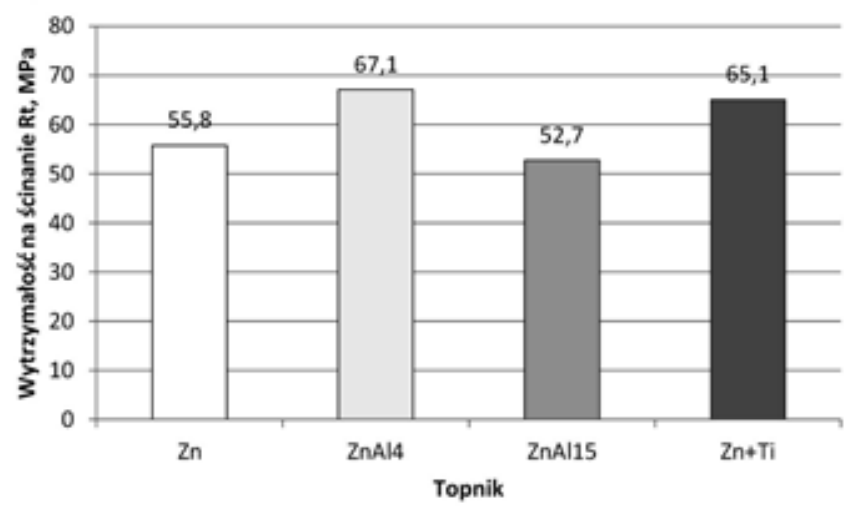

Rys. 3. Wytrzymałość na ścinanie $\left(R_{t}\right)$ połączeń aluminium lutowanych płomieniowo z użyciem lutów cynkowych i topnika Aluflux Cs Powder

Fig. 3. Shear strength $\left(R_{t}\right)$ of aluminum flame soldered using of zinc solders and Aluflux Cs Powder flux joints

w specjalnych uchwytach zaprojektowanych tak, aby próbki poddawane były jedynie siłom ścinającym, bez udziału naprężeń zginających (rys. 2). Powierzchnia ścinania wynosiła dla każdego połączenia lutowanego aluminium $314 \mathrm{~mm}^{2}$. Próby ścinania prowadzono na maszynie wytrzymałościowej Instron 4210, przy prędkości przesuwu belki poprzecznej maszyny równej $0,5 \mathrm{~cm} / \mathrm{min}$.

Statyczną próbę ścinania połączeń lutowanych wykonano na trzech próbkach dla każdego użytego spoiwa.

Średnie wartości wytrzymałości na ścinanie połączeń lutowanych z użyciem różnych spoiw przedstawiono na rysunku 3.

Uzyskane wyniki statycznej próby ścinania połączeń aluminium EN AW-1050, lutowanych różnymi lutami cynkowymi, wykazały, że największą wytrzymałość $67,1 \mathrm{MPa}$ uzyskały połączenia wykonane z użyciem spoiwa eutektycznego ZnAl4. Wytrzymałość połączeń lutowanych $z$ użyciem cynku $z$ dodatkiem tytanu $(\mathrm{Zn}+\mathrm{Ti})$ była zbliżona do wytrzymałości połączeń wykonanych z użyciem lutu ZnAl4 i wynosiła $65,1 \mathrm{MPa}$. Znacząco niższą wytrzymałość połączeń, odpowiednio 55,8 i 52,7 MPa, uzyskano z użyciem czystego cynku jako spoiwa oraz stopu ZnAl15.

\section{Badania metalograficzne połączeń lutowanych}

Badania metalograficzne połączeń lutowanych przeprowadzono na mikroskopie świetlnym MeF4A firmy Leica. Próbki do badań mikroskopowych przygotowano, szlifując je na papierach: 80, 320, 1000 i 2500 , a następnie polerowano na płótnach polerskich z dodatkiem zawiesiny polerskiej - kolejno diamentowej i korundowej o wielkości ziarna odpowiednio 3 i $0,05 \mathrm{~mm}$. Mikrostrukturę połączeń lutowanych 


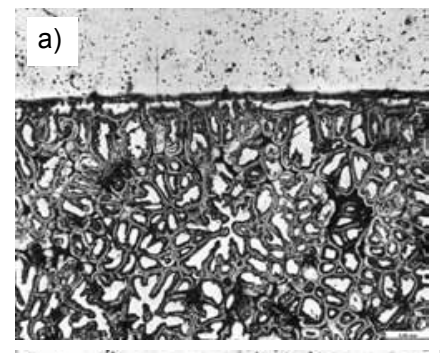

c)
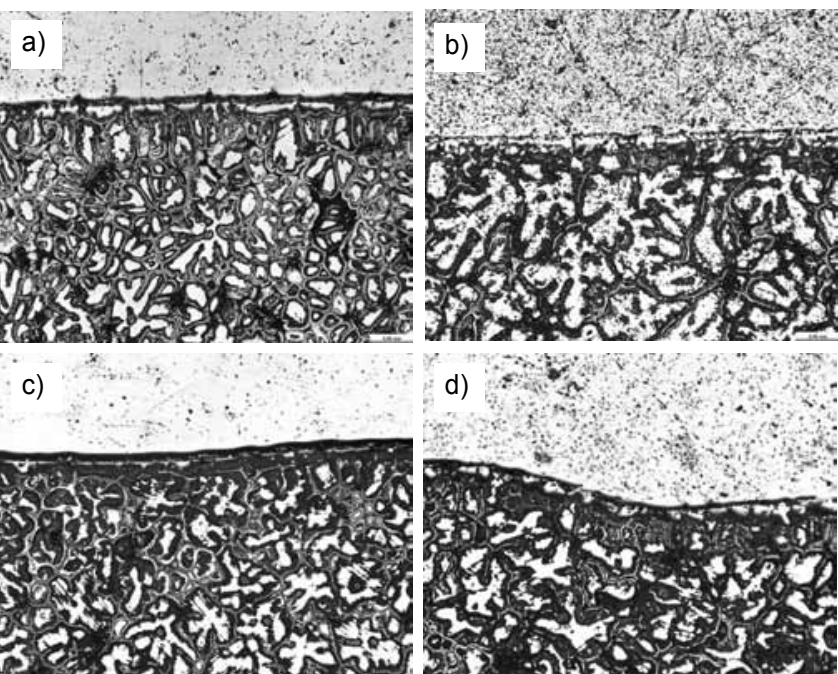

Rys. 4. Mikrostruktura przejścia lutowina-materiał podstawowy połączenia lutowanego spoiwem: a) ZnAl4, b) ZnAl15, c) Zn+Ti, d) Zn Fig. 4. Microstructure of solder-base metal boundary in the soldered joint with the use of: a) ZnAl4, b) ZnAl15, c) $\mathrm{Zn}+\mathrm{Ti}$, d) $\mathrm{Zn}$ ujawniono przez trawienie próbek tytanowych w odczynniku Kellera o składzie chemicznym (w \% obj.): $2 \% \mathrm{HF}+1,5 \% \mathrm{HNO}_{3}+2,5 \% \mathrm{HCl}+94 \% \mathrm{H}_{2} \mathrm{O}$. Obserwacjom poddano strefę rozpuszczania i wzajemnej dyfuzji pomiędzy lutowiną a materiałem lutowanym. Wyniki badań mikroskopowych przedstawiono na rysunku 4.

Analizując wyniki badań mikroskopowych, zauważyć można nieznaczną różnicę wielkości ziarna dla stosowanych spoiw. I tak w strukturze lutowiny wykonanej przy użyciu stopu ZnAl15 widać, że ziarna są większe niż ziarna w lutowinach wykonanych przy użyciu stopu ZnAl4 oraz $\mathrm{Zn+Ti,} \mathrm{co} \mathrm{może} \mathrm{mieć}$ bezpośredni wpływ na niższe właściwości wytrzymałościowych uzyskanych połączeń lutowanych. Dokładne zbadanie wpływu tytanu w cynku używanego jako spoiwa na strukturę połączeń lutowanych oraz zmiany zachodzące na linii rozpuszczania i wzajemnej dyfuzji wymagają dokładniejszych badań z użyciem elektronowej mikroskopii skaningowej.

\section{Wnioski}

Niewielki dodatek tytanu do cynku powoduje znaczne zwiększenie zwilżalności powierzchni aluminium w stosunku do zwilżalności powierzchni aluminium czystym cynkiem oraz stopami Zn-Al.

Dodatek tytanu do cynku jako spoiwa do lutowania znacznie zwiększa wytrzymałość połączeń lutowanych aluminium w stosunku do wytrzymałości połączeń wykonanych przy użyciu czystego spoiwa cynkowego i jest zbliżona do wytrzymałości połączeń wykonanych przy użyciu lutu ZnAl4.
Zwiększanie zawartości aluminium w spoiwach Zn-Al do pewnej granicznej wartości powoduje zwiększanie właściwości wytrzymałościowych stopu oraz poprawę zwilżalności aluminium, a po jej przekroczeniu zmniejszenie zarówno zwilżalności, jak i wytrzymałości uzyskanych połączeń lutowanych.

Topnik NOCOLOK przeznaczony do lutowania twardego aluminium - choć zapewnia bardzo dobrą zwilżalność - to ze względu na trudno usuwalne pozostałości topnikowe nie powinien być używany do lutowania aluminium spoiwami cynkowymi.

\section{Literatura}

[1] Cooper K.P., Jones H.N.: Microstructural evoluation in rapidly solidified Al-Cu-Si ternary alloys. Journal of Material Science 36/2001, s. 5315-5326.

[2] Radomski T., Ciszewski A.: Lutowanie, WNT, Warszawa 1985.

[3] Movahedi M., Kokabi A.H., Madaah H.R.: An investigation on the soldering of $\mathrm{Al} 3003 / \mathrm{Zn}$ sheets. Materials Characterization $60 / 2009$, s. $441-446$.
[4] Dai W., Xue S., Lou J.: Torch brazing 3003 aluminum alloy with $\mathrm{Zn}$-Al filler metal. Transactions of Nonferrous Metals Society of China, 22/2012, s. 30-35.

[5] Krajewski W.: The Effect of Ti Addition on Properties of Selected Zn-Al Alloys. Physica Status Solidi, 2/1995, s. 389-399.

[6] Schwartz M.: Brazing, Wyd. 2, ASM International, Materials Park, Ohio 2003. 